\title{
RAMOS NÚÑEZ, Carlos. Derecho, tiempo e bistoria. Discursos académicos. Lima: Legisprudencia.pe, 2013, 129 p.
}

El profesor Carlos Ramos Núñez reúne algunas de sus disertaciones preparadas con ocasión de las distinciones que ha recibido. Todas ellas recogen las reflexiones del autor surgidas a partir del fructífero cultivo de la historia del derecho.

La primera parte, titulada "El derecho como signo. Apología de la historia social del derecho", recoge el discurso pronunciado como padrino de la Maestría de Derecho Civil de la Pontificia Universidad Católica del Perú. Resalta la formación legalista que suele imperar en las facultades de derecho de las universidades peruanas y en la necesidad de ampliar esta corta perspectiva mediante asignaturas de derecho romano, historia del derecho o derecho comparado.

El autor se apoya en una idea clave: la íntima relación entre derecho y sociedad. En ese sentido, la historia es un elemento constitutivo del derecho. El derecho tiene obligatoriedad según los valores que la sociedad encarna. El derecho presupone el consentimiento de la sociedad y los valores que esa sociedad refleja. De lo contrario, el derecho sería una imposición. En consonancia con la idea anterior, la historia del derecho que propone Ramos Núñez es necesariamente una historia social del derecho que no se limita a repasar el incesante cúmulo de leyes promulgadas a lo largo de la historia. Asimismo, el autor establece una relación entre el legalismo y cierta historiografía jurídica positivista que remarca la continuidad y privilegia las normas como fuente histórica. 
La necesidad de cooperación entre historiadores del derecho e historiadores generales es el tema de su segundo discurso, realizado con ocasión de su incorporación como miembro de número de la Academia Nacional de Historia. Parte de la frecuente incomprensión a la que se ve sometido el historiador del derecho. Para sus colegas juristas, es "demasiado historiador" y a más de uno le parece una verdadera pérdida de tiempo dedicar esfuerzos para estudiar el pasado cuando contamos con un innumerable cúmulo de problemas jurídicos por resolver en la actualidad. De otro lado, el historiador del derecho se muestra "demasiado jurista" para los cultivadores de la ciencia histórica.

Sin embargo, la colaboración entre historiadores del derecho es imprescindible. El historiador del derecho necesita los métodos y encuentros de la historia general. Además, el historiador general puede aprovechar los conocimientos jurídicos que aparecen en los expedientes judiciales que suele consultar para documentar sus investigaciones.

A continuación, realiza un recorrido histórico para mencionar a los miembros de la Academia Nacional de Historia de formación jurídica: Luis Antonio Eguiguren, Oscar Miró Quesada de la Guerra, Luis Alberto Sánchez, José Luis Bustamante y Rivero, Ella Dunbar Temple, Jorge Basadre Grohmann, Guillermo Lohmann Villena, Félix Denegri Luna, José Manuel Pease García-Irigoyen, José Agustín de la Puente y Candamo y Fernando de Trazegnies Granda. De esta manera, muestra cómo la historia del derecho constituye una vía privilegiada para la mayor comprensión de la historia de las instituciones.

"Muerte y resurrección de las instituciones jurídicas" es el título del discurso de su incorporación como miembro de número de la Academia Peruana del Derecho. Tras una semblanza de César Augusto Mansilla Novella, notable procesalista a quien reemplaza en la lista de miembros de la Academia, 
establece un sugerente contrapunto entre la ruptura y continuidad en algunas instituciones jurídica. Uno de los ejemplos más elocuentes es el de la prueba tasada. Aunque podría pensarse que había quedado desfasada aquella antigua institución jurídica por la que el testimonio de tres mujeres equivalían al testimonio de un varón, la ley sobre la prueba de ADN en los juicios de filiación extramatrimonial es clara muestra de su actualidad.

Finalmente, se recoge el discurso pronunciado con motivo de las celebraciones por el centenario del Colegio de Abogados de Arequipa. En sus páginas se reconstruye la gestación de este cuerpo profesional y se presentan las iniciativas editoriales impulsadas desde distintas regiones del Perú. En este contexto, la revista $E l$ derecho se ha convertido en un verdadero espacio para el debate sobre los temas que preocupan a los miembros del Colegio de Abogados de Arequipa desde su primer número publicado en 1914. La polémica sobre el divorcio, la problemática indígena y los temas laborales tienen un lugar preponderante en sus páginas.

Espero que el lector comparta la siguiente consideración tras leer este libro y la producción de Ramos Núñez: La historia del derecho puede resultar de gran utilidad para construir el futuro en la medida que nos permite captar el sentido del presente. No se debe olvidar que los historiadores del derecho somos juristas que nos preguntamos sobre el derecho y, en esa pregunta, acudimos a la historia. Para especular sobre problemas jurídicos se puede acudir al ordenamiento jurídico vigente, al derecho comparado y a la filosofía. Confío en que la perspectiva interdisciplinaria alentada actualmente por diversos centros de investigación contribuya a un verdadero diálogo entre todos los cultivadores de las ciencias sociales y humanísticas.

Carlos Hugo Sánchez Raygada Universidad de Piura 